A full account of this particular worm, with anatomical illustrations, is given in the Journal of the Royal Microscopical Society for October, I881, by Dr. Charles Stewart, secretary of the Society. The bore-holes, after passing through the oakum of the inner sheathing, either pursue a tortuous course along the surface of the guttapercha core, or go right into the copper wire, thereby causing a "dead earth" fault. Dr. Stewart classes the worm as one of the Eunicidæ, but proposes for it the generic name of Lithognatha worslei, because of its possessing a pair of calcareous mandibles or cutting jaws, and after Capt. Worsley, the Commander of the repairing ship which picked up the worm-eaten cable. The pair of calcareous jaws, in addition to three pairs of chitinous ones, is the most remarkable feature about the animal, and the white plates which form them make the creature look as if it were in the act of swallowing a tiny bivalve shell.

The best protection hitherto formed against it is to cover the core with a ribbon of sheet-brass, laid on without a lap. First the gutta-percha is covered with cloth, then the brass is overlaid. Canvas is then put over the brass, and the hemp and iron wires over all. A close layer of iron wires is not a sufficient protection, for the worm can sometimes wriggle in between the wires where they are not close enough; and, moreover, the rapid decay of iron wires in tropical seas is certain to leave the core a prey to these pests in a few years.

The Eastern Extension Telegraph Company also exhibit some interesting samples of stones picked up from the sea-bottom; for example, limestone blocks and shells bored by the bivalve, Saxicava ragosa, the worm Sabella, and the sponge Hymeniacidon celata; wood honeycombed by the teredo, a red stone pitted by the bivalve shell (pholas), and a ferruginous flaky stone brought up from the bottom between Penang and Singapore. Most interesting, however, of these inanimate waifs is a flat piece of black flinty rock hollowed into cuplike pits by the sucking feet of the sea-hedgehog. The pits are excavated as lairs for the animal and some of them are nearly three inches in diameter by one inch deep. To make the rocky bed softer to the feel, the hedgehog bas lined it with a calcareous enamel, probably secreted by its body, much in the same way as the pearl oyster coats its shell.

In the earlier days of submarine telegraphy, Sir William Thomson declared the life of a cable to be practically inviolable; and Robert Stephenson, on the other hand, was of opinion that no cable would last out ten years. The latter view has proved the more correct, for the average life of a cable hitherto has been about eleven years. Thanks to the improved means of repairing them, however, the outbreak of faults does not mean the loss of a cable, for these flaws can be cut out in water, however deep, and the cable put to rights again. Indeed every cable company expects a recurrence of faults, and provides a fully-equipped repairing ship always on the spot. A fine model of such a ship is exhibited by the Post Office, after the designs of Mr. R. S. Culley. Messrs. Johnson and Phillips also exhibit a variety of buoys and grapnels for cable operations. The ordinary grapnel is liable to have its prongs broken off in dragging over a rocky bottom, as may be seen from one exhibited which had every prong bent back among the coral reefs of the Brazilian coast. Centipede grapnels are therefore fitted with removable prongs; and Mr. A. Jamieson has invented a grapnel with spring teeth which bend back when they meet a rock, so as to slip over it, but catch and hold the cable. A sample of this grapnel is shown in the Western Gallery, and a sample of Messrs. Johnson and Phillips' grapnel for cutting the cable and holding one end is shown in front of the Roman court, together with a very large buoy for buoying the cable in deep water. A very convenient and novel "mark" buoy for marking positions in cable work is exhibited by the same firm in the Western Gallery. The buoy is suspended by a line from the ship's quarter or stern, and when the line is cut, the buoy drops into the water. The copper float ball (see Fig. 4) is then raised, and lifts a detent which allows the drum of steel wire to revolve. The centipede anchor then sinks to the bottom, and moors the buoy. A winch handle is provided, so that the moorings can be recovered if need be, but the cost of the sinker, drum, and wire is so slight that it may readily be abandoned. While upon the subject of deep-sea operations, we may also mention the "nipper lead" of Mr. Lucas, by which specimens of the sea-bottom are caught in two spoons or tongs hinged to the bottom of the lead, and kept apart by a trigger arrangement, which is sprung by the lead striking the bottom.

Coming now to the working of submarine cables, there are several very neat mirror galvanometers exhibited by Messrs. Latimer Clark, Muirhead, and Co. The Eastern Telegraph Company exhibit the siphon recorder of Sir William Thomson, working through one of Dr. Muirhead's artificial cables on the duplex system, the counter instrument being placed at the stall of the School of Telegraphy. The bold electromagnets of this fine instrument have been excited hitherto by Sir W. Thomson's large tray-form of Daniell cell ; but quite recently Mr. Clement Chevallier, electrician to the Eastern Telegraph Company at Aden, has substituted permanent magnets, with a great gain in economy. These magnets were specially made by Mr. Le Neve Foster, at Silvertown, and their magnetic power is much heightened by a small percentage of tungsten in the steel. An interesting experiment, showing the retardation of signals through a long submarine cable, is made by the School of Telegraphy. Ten mirror galvanometers, throwing ten lightspots in a vertical row on a white screen, are connected in turn at different points of a long cable, and the travel of the charge when the circuit is closed by a key is shown by the successive movements of the light-spots across the screen.

Mr. C. F. Varley, F.R.S., who by his application of condensers to the submarine circuit did so much to improve cable signalling, has a very interesting exhibit of his past inventions. These include his gravity battery patented in 1854 (No. 2555), and repatented in $186 \mathrm{I}$ by Menotti, whose name it bears. In the same patent the sulphate of mercury battery, subsequently known as the Mariè-Davy, was also described. This patent, like most of Mr. Varley's, was very rich in devices, and contains his application of the condenser not only to telegraphy, but to electric lighting, a plan subsequently patented by Jablochkoff. Mr. Varley's exhibit also includes the first polarised relay used in this country, and the rotary electrical machine made and patented in 1860 , and held by him to be the parent of the Holtz and other induction machines, such as the mousemill of the siphon recorder and the replenisher of the quadrant electrometer. But it is probable that Mr. Varley's claim must give way in favour of M. Belli, who invented a similar induction machine many years ago, which the writer saw in the Retrospective Museum of the recent Paris Electrical Exhibition.

\section{THE EARLIEST USE OF THE INCANDESCENT} ELECTRIC LIGHT

\section{$A$ CORRESPONDENT writes:-}

A The following extract from a memoir by Sir William Grove, published more than thirty-six years ago, will be of interest to future historians of the progress of lighting by electricity. The memoir is entitled "On the Application of Voltaic Ignition to Lighting Mines," by W. N. Grove, F.R.S., and is published in the Philosophical Magazine, May, 1845 . It begins by stating that M. De la Rive had proposed the use of the voltaic are for illumi- 
nating mines; it describes the apparatus employed by him, and the difficulties that prevented its practical application, and continues as follows :-

"I substituted the voltaic ignition of a platina wire for the disruptive discharge. Any one who has seen the common lecture-table experiment of igniting a platina wire by the voltaic current nearly to the point of fusion, will have no doubt of the brilliancy of the light emitted; although inferior to that of the voltaic arc, yet it is too intense for the naked eye to support, and amply sufficient for the miner to work by. My plan was then to ignite a coil of platinum wire as near to the point of fusion as was practicable, in a closed vessel of atmospheric air, or other gas, and the following was one of the apparatus which I used for this purpose, and by the light of which I have experimented and read for hours :-A coil of platinum wire is attached to two copper wires, the lower parts of which, or those most distant from the platinum, are well varnished; these are fixed erect in a glass of distilled water, and another cylindrical glass closed at the upper end is inverted over them, so that its open mouth rests on the bottom of the former glass; the projecting ends of the copper wires are connected with a voltaic battery (two or three pairs of the nitric acid combination), and the ignited wire now gives a steady light, which continues without any alteration or inconvenience as long as the battery continues constant, the length of time being of course dependent upon the quantity of the electrolyte in the battery cells. Instead of making the wires pass through water, they may be fixed to metallic cups wellluted to the necks of a glass globe.

The spirals of the helix should be as nearly approximated as possible, as each aids by its heat that of its neighbour, or rather diminishes the cooling effect of the gaseous atmosphere; the wire should not be too fine, as it would not then become fully ignited; nor too large, as it would not offer sufficient resistance, and would consume too rapidly the battery constituents; for the same reason, i.e. increased resistance, it should be as long as the battery is capable of igniting to a full incandescence."

The memoir concludes with the description of experiments on the illumination power of this contrivance under different conditions.

\section{THE ENGLISH ECLIPSE EXPEDITION}

THE following communication, under date lat. N. $37 \cdot 8$, long. E. II IO, April 27, has appeared in the Daily Newe, from the special correspondent of that paper with the English Eclipse Expedition :-

Your correspondent so far has not had a very easy time of it, although it must be confessed his difficulties have been in no way connected with lack of material. Chronicling attempt; to advance beyond the frontiers of the known must always be a pleasant task to the chronicler, who is thus enabled to be among the first to reap the rich intellectual rewards always gained, or nearly always gained, in such forays. But when the task brings him in full view of other interests, and especially when it compels him to observe phenomena for himself, a correspondent's task may become complicated beyond measure, and not only the embarras de richesses, but even a mental revision of his instructions, however precise they may have been, may give him trouble. Thus, in the present case, my clear duty is to keep pace with the thoughts and doings of the Eclipse party now on the Kaisar-i-Hind, between Gibraltar and Malta; but am I therefore to be blind to the fact that each $P$. and $O$. ship does not leave Gravesend with two tons of telescopes and eyes to use them, and that the infusion of a scientific party into the general run of passengers on this the most important of England's seaways, cannot but cause what our American cousins would call a "ripple" on the ordinary routine of ship-life.
Those who have made their way to the far East many times, and who are therefore quite familiar with this routine, will at once recognise the possibility that at first such rarce aves were looked at askance. Was there not at least some strange power of divining secrets in sextants, spectroscopes, and cameras brought now and then, and with a kind of furtive air, from hidden recesses? And this being so, what conduct was more natural on the part of the non-scientific members of the party, than that they should show a keen anxiety to assure everybody that they at least knew next to nothing of science-in short, that though they might deplore these strange and aberrant tendencies, they were powerless to interfere, even if the studies were less harmless than they believed them to be. This, at first, of course confirmed the general impression, but it did not take long for the ice to melt ; the strange feeling soon wore off, and after a fierce gale which the Kaisar-i-Hind encountered in the Bay of Biscay had abated, the keenness of everybody on board to hear something of a world of marvels new to most of them, and the anxiety of every servant of the $P$. and $O$. Company, from captain to boatswain, to help, whenever help was needed, were the predominant features.

The delight of the Somali boys at being photographed was a sight to see, their broad grins being in strange contrast with the evident anxiety of the Arabs among the crew to escape the influence of such a possible evil eye. While this is going on in one part of the ship, the reflection of the summer sun shimmering from a thousand Mediterranean waves through which the noble ship ploughs her way on an even keel is utilised to show the wondrous work which has already been done by the spectroscope. Nor are the other worlds, still left to conquer, forgotten in the demonstration; among them, those secrets of the Sun which it is hoped may be unveiled during the coming precious seventy seconds. And this brings me to the proper subject matter of the present letter. What, then, are the astronomers going to do? or, to put it more modestly, what are they going to try to do? Before a categorical answer can be given to this question there is some preliminary matter to be got over; we have, in fact, to consider the changes in thought and methods introduced by ten years of work. A volume might be written on this, but a very brief exposé is really all that is required on the present occasion. The brilliant achievements of physical astronomers in the domain of solar physics during the last twenty years bave dealt in the main with the chemical and physical construction of the atmosphere of our central luminary; that is, those parts of it which are furthest from the centre. In fact, it has been a question of meteorology, and not a question of geology, to use terrestrial equivalents. One of the first things made absolutely certain was that the outer atmosphere for tens and perhaps hundreds of thousands of miles above the surface of the round orb we generally see and call the Sun, is intensely hot-hot enough to have its clouds built up of vapour of iron, as in our own air we have clouds built up of the vapour of water. Next, as the work went on, two things happened. First, certain and sure evidence was obtained that the outer atmosphere extended much farther from the sun than had been previously supposed by those most competent to form a just opinion ; and, further, while the extent of the atmosphere was thus engaging attention, the chemical inquiry had been carried so far that we thought we were justified in saying, not only that the sun's atmosphere contained just such substances as ours would do if our little earth were suddenly turned into a mass of vapour, but that certain substances occupied such and such positions in the atmosphere, while others were to be sought for elsewhere.

Thus outside all, it was imagined, there was a substance about which we know nothing here, because we cannot find anything which produces the same spectrum. Inside 